\title{
Reuse of ideas and concepts for creative stimuli in engineering design
}

\author{
Howard, Thomas J.; Culley, Steve J.; Dekoninck, Elies A.
}

Published in:

Journal of Engineering Design

Link to article, DOI:

$10.1080 / 09544821003598573$

Publication date:

2011

Link back to DTU Orbit

Citation (APA):

Howard, T. J., Culley, S. J., \& Dekoninck, E. A. (2011). Reuse of ideas and concepts for creative stimuli in engineering design. Journal of Engineering Design, 22(8), 565-581. https://doi.org/10.1080/09544821003598573

\section{General rights}

Copyright and moral rights for the publications made accessible in the public portal are retained by the authors and/or other copyright owners and it is a condition of accessing publications that users recognise and abide by the legal requirements associated with these rights.

- Users may download and print one copy of any publication from the public portal for the purpose of private study or research.

- You may not further distribute the material or use it for any profit-making activity or commercial gain

- You may freely distribute the URL identifying the publication in the public portal

If you believe that this document breaches copyright please contact us providing details, and we will remove access to the work immediately and investigate your claim 


\section{Reuse of ideas and concepts for creative stimuli in engineering design}

Authors: T. J. Howard'; S. J. Culley²; E. A. Dekoninck ${ }^{2}$

Affiliation: 1. Engineering Design and Product Development, Technical University of Denmark, Denmark

2. Mechanical Engineering, University of Bath, Claverton Down, Bath, UK

This is an electronic version of an article published in HOWARD, T.J., CULLEY, S.J. and DEKONINCK, E.A., 2010. Reuse of Concepts for Creative Stimuli in Engineering Design. Journal of Engineering Design, Vol. 22, No. 8, Aug 11, pp565-581 (DOI: 10.1080/09544821003598573). is available online at:

http://www.tandfonline.com/doi/abs/10.1080/09544821003598573

\section{Abstract}

Creative idea generation is essential to novel concept development and ultimately innovation. The following paper describes an extensive industry-based study investigating the use of creative stimuli during a brainstorming session at the conceptual stages of design. A new approach to retrieving creative stimuli referred to as 'Sweeper' is proposed, which sources stimuli internal to a company's information repository. This creative stimuli tool is then compared to other creative stimuli tools using objective, industrially grounded performance criteria. This study provides an arguably much needed real, industrially-based experiment regarding brainstorming. The results and observations suggest that having a guided approach to sourcing creative stimuli is very beneficial. The use of the TRIZ contradiction matrix and inventive principles is also shown to be a good example of a guided approach in terms of increasing creative performance. However, the Sweeper tool using internally sourced stimuli provides a method that is useful and more a practical alternative, as it is based firmly in the domain of activity.

\section{Introduction}

It has become widely accepted that business survival and prosperity is strongly attributed to the ability to innovate (Prahalad and Ramaswamy 2003, Campos et al. 2004, Soosay and Hyland 2004, Taghavi et al. 2004). In order to harness this ability, many engineering companies have specific innovation and R\&D departments, developing new products through strategically constructed innovation processes. However, ultimately, innovation begins with the generation of creative ideas (Amabile 1996, Mumford 2000, Kristensson et al. 2002) where creative idea generation is an integral part of design which fundamentally determines the type of designs produced.

The process of generating creative ideas is enhanced by providing creative individuals three main elements; nurture, freedom (Mauzy and Harriman 2003) and time (Sternberg and Lubart 1993, Frey 1999). However, such is the nature 
of industry that time pressures often dominate, requiring rapid idea and concept generation from engineering designers. The need for increased quality of ideas is compromised by the time in which they are to be produced. Thus, creative tools are required to aid the designer to produce more 'creative' ideas in short periods of time.

Though there are many techniques and tools for generating creative ideas, brainstorming is undoubtedly one of the most popular creative techniques used by organisations (Faure 2004). However, this technique does not come without its limitations (Isaksen and Gaulin 2005). In a recent study of several industrial case studies, it was shown that the rate of idea generation during brainstorming decreases slowly and steadily after 30 minutes, with a dramatic decrease in idea quality after just 20 minutes (Howard et al. 2009). It was also shown that the introduction of stimuli into the brainstorm sessions was beneficial and helped to maintain idea frequency and quality (Howard et al. 2008a).

It could be argued that a creativity support tool should aid a designer during any phase of the creative process, either; as a task framing tool during the analysis phase; as an idea generation tool during the generation phase; or as a selection or evaluation tool in the evaluation phase (Howard et al. 2007, Howard et al. 2008b). This paper will concentrate on what can be thought of as "generation tools". Though there are several approaches for categorising such tools (Zusman and Zlotin 1999, Lubart 2005, Pahl et al. 2007) the authors do so into three categories (Howard 2008), creative-analysis tools, -thinking tools and -stimuli tools.

Creative analysis tools aim to aid problem definition and to identify opportunities and resources. These tools essentially encourage exploratory thinking within the problem space, where the emphasis is not on forming a solution but redefining the problem. This may help designers, as solutions proposed for the redefined problem may be more workable than solutions proposed for the original problem. These creative analysis tools would include: 'Problem reversal', 'Synectics' (Gordon 1961), 'Redefining a problem/opportunity', 'TRIZ problem formulation' and 'TRIZ system operators' which assesses the system being worked on in terms of its time line and systems level (Mann 2002). Creative thinking tools aid the designer's exploration of the solution space until they are illuminated with a valid solution. Typical creative thinking tools would include: 'Brainstorming' (Osborn 1953), 'Mind maps', 'Storyboarding', '6 Hats' (De Bono 1985) and 'Role playing'.

The final category is for the creative stimuli tools. These tools simply propose stimuli, which is information used to relate to the problem with the intention of inspiring new solutions. Typical creative stimuli tools are: 'random inputs', 'TRIZ 76 standard solutions', 'Forced analogy', the 'TRIZ Contradiction matrix and 40 principles' (Altshuller 1984, Altshuller 1999), and also the concept reuse tool, referred to as "Sweeper" proposed in section 3.

The purpose of this paper is to show the benefits of using information in the form of design concepts related to the domain, to inspire new ideas. From this point forward, all information provided for or used for the purpose of inspiring new ideas will be referred to as stimuli. To achieve this, firstly the tools will be compared in the following section in which a number of performance criteria are produced. In section 3 the proposed Sweeper creative stimuli tool is fully introduced. The experimental method (section 4) is then detailed for the comparison of the creative stimuli tools before the results from the industry based experiments are provided (section 5) and then concluded in section 6 . 


\section{Theory}

In this section the creative stimuli tools are defined and categorised into 4 groups within a 2 by 2 matrix (Table 1, section 2.1). The example tools from each group are then described (section 2.2) before the performance criteria used to assess them (section 2.3). The section ends with a set of expected outcomes (section 2.4) to be tested during the experimental work.

\section{Creativity tool matrix}

There are few categorisation schemes within the literature for the different types of creative stimuli tools. Previously, related schemes have described the types of stimuli in terms of function, behaviour, form and knowledge entities (Benami and Jin 2002). Others have categorised the stimulus as heterogeneous or homogeneous (Nijstad et al. 2002) with respect to the previous idea produced. However, none of the research from the literature, nor any of the commercial creativity tools reviewed, have considered the potential of stimuli generated internal to the industrial domain which could be linked to the distance of abstraction of the stimulus from the problem (Amabile 1982, Santanen et al. 2004, Santanen and De Vreede 2004). This paper will thus analyse the potential of stimuli generated from information sources internal to the industrial domain in which the design task was set.

The categorisation of stimuli tools used in this paper is described by a $2 \times 2$ matrix (Table 1) constructed from the following two categories:

Source: where the stimuli are drawn from. This can either be internal or external to the industrial domain in which the task is set.

Retrieval: the strategy for stimuli retrieval. The stimuli can either be retrieved randomly, or, guided by an abstracted framework to make the stimuli applicable to the problem or task.

Table 1. Matrix of creative stimuli tools

\begin{tabular}{llll}
\hline & & Retrieval & \\
\cline { 3 - 4 } & & Random & Guided \\
Source & External & $\mathrm{A}$ & $\mathrm{B}$ \\
& Internal & $\mathrm{C}$ & $\mathrm{D}$ \\
\hline
\end{tabular}

The potential of internally generated stimuli will be validated through the evaluation of the performance of creative stimuli tools in matrix positions $C$ and $D$ (Table 1 ) relative to the externally generated creative stimuli tools in positions $A$ and $B$ (Table 1). In particular the guided Sweeper approach (section 3 ) in matrix position D will be compared against the other stimuli tools. Each of these tools is further detailed in section 2.2 with particular emphasis on the explanation of the 'retrieval' criterion shown in the matrix. 


\section{Creativity tools within the matrix}

The four different categories of creative stimuli tools will now be detailed along with an example stimulus for each category of tool (see Table 2 for the example stimuli). It is worth noting at this point that the stimuli are information with the intention to inspire the designer with new idea. This information may take the form of a principle, an idea, a concept or random information. For the purpose of this research a single PowerPoint slide was used to convey each stimulus (see Table 2 for example).

\section{Type A creative stimuli tools}

Type A tools draw on random stimuli from sources external to the industrial domain in which the problem is set. From the Zusman et al. (1999) matrix, typical tools would include 'serendipity', 'forced analogy', 'relational words' and most representative 'random input'. To simulate the Type A creative stimuli tool for purposes of this study, images were taken randomly from a popular online image bank and displayed singularly on electronic slides.

\section{Type B creative stimuli tools}

Type B tools use intelligent guiding to stimuli from sources external to the industrial domain in which the problem is set. This type of tool was made popular by TRIZ, the theory of inventive problem solving (Altshuller 1999). However, there are several other creative stimuli tools that use guided stimulus retrieval such as FuncSION (Chakrabarti and Tang 1996) and Animal Crackers (Grossman and Lloyd 2006). To simulate a Type B creative stimuli tool in this experiment, the TRIZ contradiction matrix will be used as an example. In creating the contradiction matrix, 40000 patents were classified by the design contradiction which they solved without compromise. Patterns emerged which were recorded in the form of the contradiction matrix. Every new problem can now be broken down to its contradiction and the historically appropriate solution principles can be extracted from the matrix and used as stimuli.

\section{Type C creative stimuli tools}

The Type $C$ tool draws random stimuli internal to the industrial domain in which the task was set. Though no Type $C$ tools were found during the review, designers naturally draw inspiration from internal sources. It is common to look at previous designs, particularly through catalogues and prototypes from within the domain. In order to represent this type of tool for the experiment, random concepts were selected from within the huge repository of previous design projects stored by the case company and used as stimuli.

\section{Type D creative stimuli tools}

The Type $D$ tools are tools that intelligently guide designers to stimuli internal to the industrial domain in which the task was set. Though currently no official Type $D$ tools have been observed, an possible example of one has been embodied by the Sweeper tool presented in section 3 . 
Table 2. Examples of Stimuli retrieved by each tool type

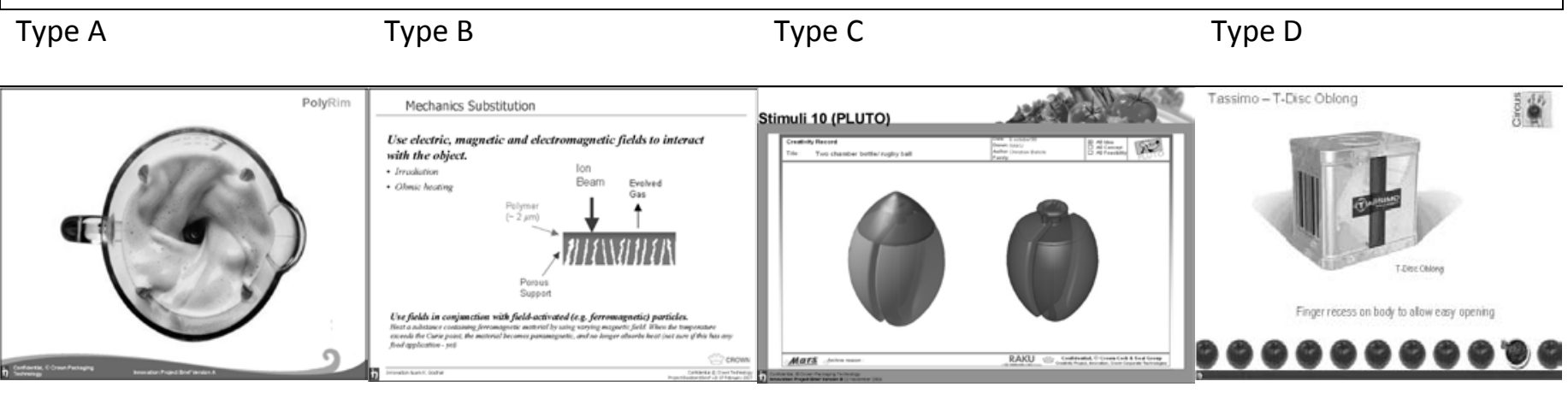

\section{Creative performance criteria}

The creative performance of a group is often measured using two dependant variables of; idea frequency (Nijstad et al. 2002, Perttula and Sipila 2007), and, idea quality (Wierenga 1998). From a broad analysis of the literature, it would appear that the creative quality of an idea is generally defined by the criteria - 'originality' (novelty) and 'appropriateness' to a task (Massetti 1996). However, if an idea is considered both appropriate and original but obvious to any designers tackling the same problem, should we consider it creative? The authors believe not and thus a third criterion: unobviousness (Howard et al. 2006) of an idea is proposed. Although there are well established theoretical definitions for these criteria for an idea's quality, these are extremely difficult to objectively measure. Table 3 states how each of the criteria will be related to the observations and data gathered whilst conducting this experiment within an industrial context.

Table 3. Dependant Variables (Success Criteria)
Variable
Definition
Frequency
How quickly ideas are being produced, or how may ideas are produced in a given time period.
Originality
Whether the idea is related to a completely new concept (original) or not (routine).
Appropriateness Whether the idea is rejected at the stage gate (inappropriate) or is selected for further exploration (appropriate).
Unobviousness
Whether the idea was generated quickly (obvious) or after a longer period (unobvious).
Due to the experimental method chosen in section 4 the performance of the creative tools will focus on the frequency, appropriateness and originality of the ideas being produced. The creative performance of the tools in terms of the unobviousness is related to the frequency of the ideas at the later stages of the brainstorms in comparison to the earlier stages. However, due to the method chosen this was difficult to analyse independently of the frequency of idea production. It is thought that each stimuli tool tested will have differing effects on each of the criteria, leading to a set of expected or hypothesised outcomes from this experiment. 


\section{Expected outcomes}

It is useful to reflect how the criteria mentioned above may be affected by the different types of creativity tools being used. The following list of possible outcomes below can suggested by the authors and can be considered to be research hypotheses for the following experiment.

Possible outcome 1: It is expected that the internal stimuli will be more recognisable to the participants of the brainstorm session and will also be more relevant to the design task and will thus stimulate a higher number of ideas.

Possible outcome2: It is thought that the internal stimuli tools will, on average, produce stimuli which is more relevant to the problem and thus will produce more appropriate ideas. However, these ideas must be of a good enough quality to be selected as gate ideas.

Possible outcome3: It is thought that the external stimuli tools will produce marginally more original ideas due to the more abstracted nature of the stimuli.

Possible outcome 4: It is thought that the guided approaches to retrieving the stimuli will show to be beneficial over the random sourcing in terms of all the performance criteria. However, it could be the case that the guidance methods used will not be appropriate for either the types of design task, or the designers undertaking them.

\section{"Sweeper" - A concept reuse creative stimuli approach}

The Sweeper tool reuses concepts from previous projects as creative stimuli. The approach used for stimuli retrieval, theoretically finds the concepts that are most relevant to the task at hand. The Sweeper tool was originally termed the IMCS (Information Management for Creative Stimuli) tool during the background research for this paper and in previous publications (Howard 2008, Howard et al. 2008a). During the research the three dimensions of the tool (see Figure 1), namely, search (section 3.1), retrieve (section 3.2) and store (section 3.3) were manually simulated for the purposes of the experiment and to establish the principle of the approach. However, it was foreseeable that the tool could be implemented as an automated version requiring minimal to no maintenance to use and populate. The IMCS tool is now being implemented within the case company under its new name of "Sweeper".

Sweeper is essentially a very efficient case based reasoning conceptual design tool, which uses the TRIZ approach to abstracting problems and finding alternative solutions. The approach creates a link between the current problem and previous problems by comparing the 'musts' and 'desirables' from the design specifications used at the host company. For a comparison, the TRIZ contradiction matrix uses abstracted design contradictions to link the current problem to previous problems. Though there are several methods by which to recall stimuli in an intelligent, guided manner, the method detailed below is one developed for a repeatable simulation of a Type $D$ tool (internal source - guided retrieval). This approach also has the potential to be self populating and fully automated being integrated with the working practice of the designers, requiring no extra input or analysis in order to retrieve the most appropriate stimuli. 


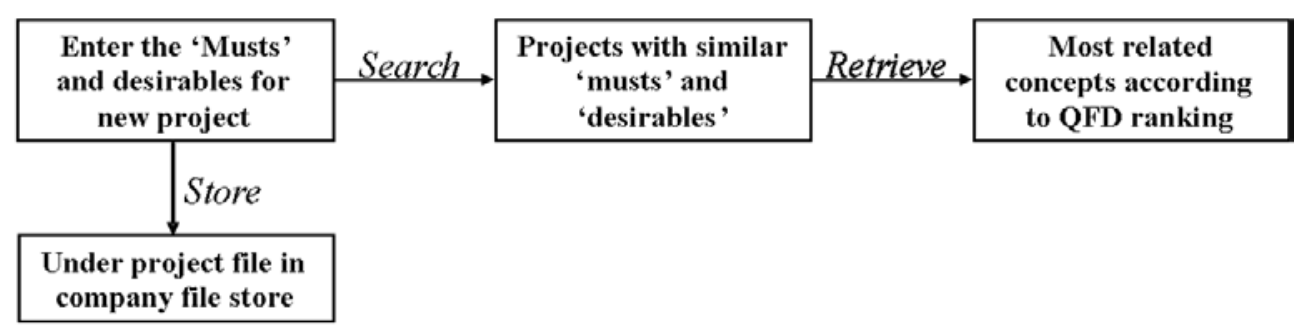

Figure 1. Customised Search, Retrieve and Store approach of the Sweeper tool

\section{The search dimension}

At the host company, new project brief documents (Figure 3) are constructed from standard brief templates (Figure 2). In the construction of a new brief, musts and desirables are entered and linked to pre defined categories. To execute the Sweeper approach a search would be undertaken through the project files to find other project briefs containing the most accurately matched musts and desirables. For initial experimentation purposes this was undertaken by key word searching through the project briefs (Figure 4).

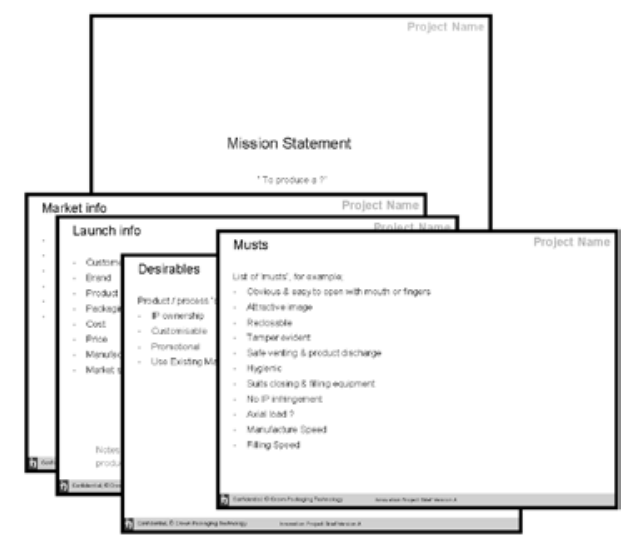

Figure 2. Brief templates

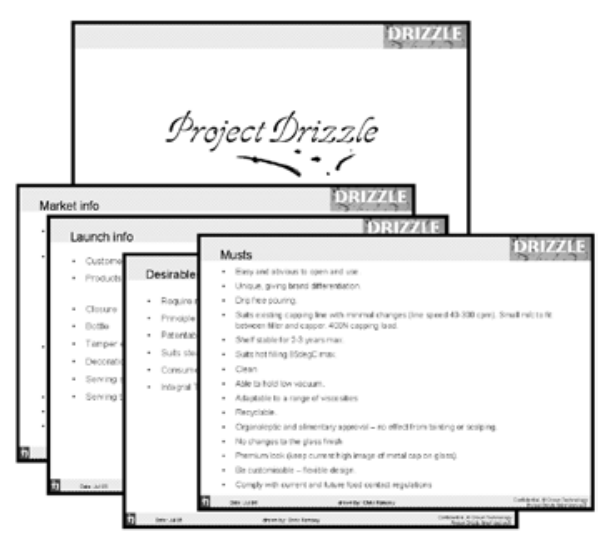

Figure 3. New briefs

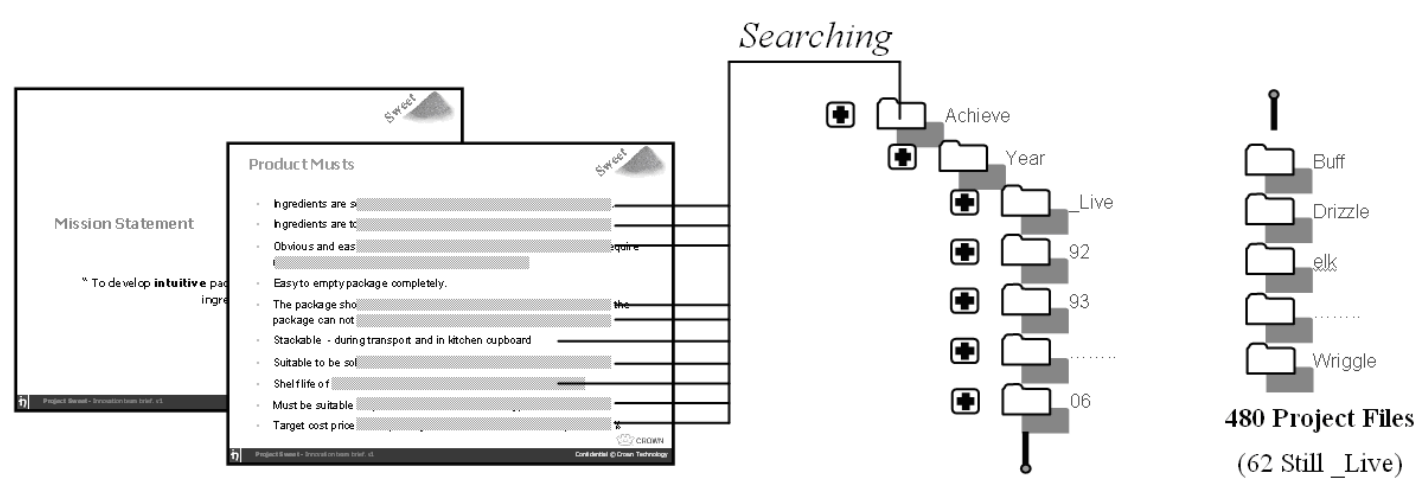

Figure 4. Searching for related project briefs 
Every time a requirement from a new brief is matched with one from a brief from an old project, that project scores one point. The project with the most points is deemed the most relevant to the new design task. However, certain 'musts' and 'desirables' are already found in the project brief template (Figure 2) and exist more commonly throughout the new project briefs (Figure 3) than other requirements. A weighting of 3 was therefore given to any matches made using newly added requirements. This is an area for future research to optimise and improve upon.

\section{The retrieve dimension}

The projects retrieved from the search are placed in rank order from the most scoring matches (including the weighting) to the least. Once the 10 most relevant projects are identified the concept images can be obtained from within the project files. The selected concepts from each project can be chosen randomly, or linked to the a concept selection matrix, termed by the case company as QFD (Cross 2000), which ranks each concept to the various requirements. The concept scoring the best with respect to the new, match requirements was selected. This method was used whenever a 'QFD' file was present within the project folder. Concepts were returned in the form of a single PowerPoint slide (see Table 2).

\section{The store dimension}

In order to make the Sweeper approach self populating and expanding, new project briefs and concepts created must be stored into a system ready for automatic retrieval at a later date. The brief must therefore be added to its project file and its musts and desirables categorised by the higher level structure. In order to do this, the musts and desirables are entered by free description and then in a computer implementation, linked via drop-down menus to the higher level headings (Figure 5) which could then be used for the search function. The concepts designed for each new project need to be saved under a consistent file name and stored within the project file along with any QFD analysis files.

\begin{tabular}{|c|c|c|}
\hline \multicolumn{3}{|l|}{ MUSTS } \\
\hline \multicolumn{3}{|c|}{ Category } \\
\hline Ingredients sold separately & Single serve & \\
\hline Obvious to open & Intuative & \\
\hline Reclosable & Reclosable & \\
\hline Easy to empty package completey & & F \\
\hline One hand opening & Single serve & $\wedge$ \\
\hline Safe venting & $\begin{array}{l}\text { Intuative } \\
\text { Reclosable }\end{array}$ & \\
\hline Hygienic & $\begin{array}{l}\text { Shelf stable } \\
\text { Sustainable }\end{array}$ & 青 \\
\hline Attractive image & \begin{tabular}{|l} 
Sustanaduct \\
Ful product release
\end{tabular} & \\
\hline No intelectual property infringment & $\begin{array}{l}\text { Stackable } \\
\text { Microwavable }\end{array}$ & $\checkmark$ \\
\hline
\end{tabular}

Figure 5. Linking musts to a higher level category 


\section{Implementing the Sweeper (the concept reuse tool) approach}

The Sweeper (the concept reuse tool) approach relies on several conditions, all of which were fulfilled by the case company. Firstly, the company must have a consistent and standard design process. Secondly, the documents containing the project brief, ideas and concepts must be consistently and appropriately named, and must be stored electronically and logically.

The store dimension for the Sweeper tool relies on a pre-constructed ontology. This approach relies on a must or desirable being inserted into the brief document, then being linked to an umbrella term from the ontology. This approach could be enhanced of supported by a facetted classification (Giess et al. 2008) enabling concepts and ideas to be linked to other supporting information regarding markets, business sector, date of conception, creator, project manager etc.

\section{Experimental method}

The method used was constructed to take advantage of a unique opportunity within an industrial innovation hub. The research methodology chosen uses an 'insider' or 'participation' action research approach (Björk and Ottosson 2007), which helps keep emphasis firmly on what designers do rather than what they say they do (Avison et al. 1999). In order to notate and capture data, protocol analysis was used successfully in similar studies (Benami and Jin 2002, Kim et al. 2005). Though in this experiment, sample sizes were small and some variables were left uncontrolled, this gave the possibility to participate and capture real design activities with professional engineers. However, all analysis and conclusions drawn from quantitative data must be done so in light of these experimental limitations.

The research method for this study was constructed around the case company's practices. The company's standard innovation process that was followed for all the case projects comprised within this experiment. It was thought that the first stage of this process, termed the ideas stage (described in Figure 6), is equivalent to the conceptual design stage (Pahl and Beitz 1984) where the authors believed this research into creative stimulation would be most effective.

\section{Ideas stage of innovation process}

In each of the case projects under study, the following process was followed consisting of components, the brief, the brainstorm meeting, the individual idea generation, the review meeting and finishing at the stage gate. The outputs are ideas, categorised by the component or sub component for which they were produced. It is worth noting that a concept is defined to be a design solution consisting of at least one functional, behavioural and structural idea (not further discussed in this paper). The concepts proposed at the gate meeting therefore consist of previously selected ideas, which are termed gate ideas (see Figure 6) 


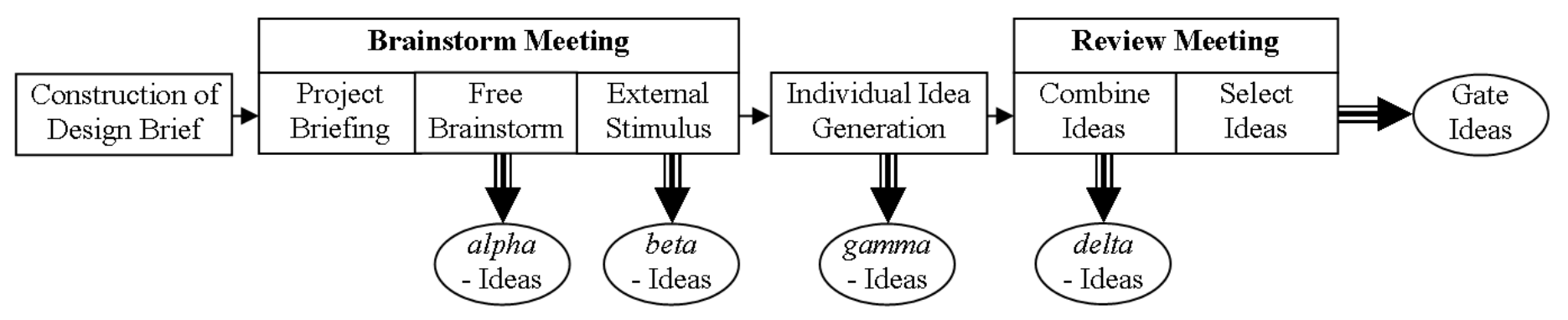

KEY

alpha-ideas: Ideas generated during free thinking brainstorm session.

beta-ideas: Ideas generated after group is exposed to prepared stimuli.

gamma-ideas: Ideas generated individually after the brainstorm session.

delta-ideas: Ideas generated by combining ideas during the review meeting.

Gate-ideas: Appropriate ideas embodied within concepts put forward at the gate meeting.

Figure 6. The first stage of the case company's stage gate innovation process

Construction of brief: Each design project studied began during the construction of the project brief. During this stage, the mission statement for the project is set, along with the various 'musts' and 'desirables' required for the design solution. The project manager is allocated and a team of approximately seven is assembled for a brainstorming session to generate solution ideas for the brief.

Brainstorm meeting: Within this session, roughly the first 30 minutes would consist of communicating the project brief to the team members whist trying to frame the problem at hand. This is commonly followed by a free thinking brainstorm lasting between 30 and 70 minutes during which alpha-ideas will be generated. Following this, the stimuli were presented in turn to aid the session. The ideas produced during this period were termed beta-ideas. This was done for the four chosen case projects (see Table 4) with no stimuli presented to the group during project 5.

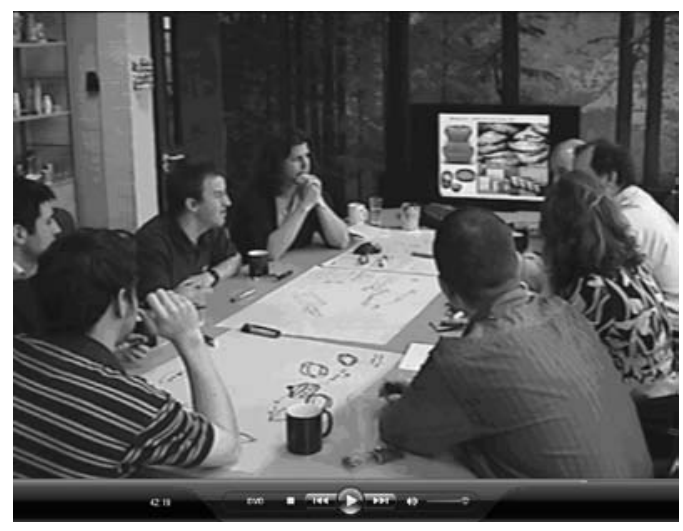

Figure 7. Screen capture of typical brainstorm meeting 
Individual idea generation: During this phase each team member is given roughly 1 week to produce 6 ideas (these ideas are to be in concept form, complete with function, behaviour and structure). These gamma-ideas can be constructed from ideas that they particularly like from the brainstorming session or as a result of a totally new idea generated. Each concept is named and drawn on an individual sheet.

Review meeting: During this review meeting team members exhibit each of their individual gamma-ideas and are encouraged to group ideas by similarities and to make new and useful combinations of the ideas, noted as delta-ideas. After all ideas have been shared the groups of ideas are refined. At this stage several of the ideas are rejected due to them being inappropriate. The project manager will then draw up the selected ideas in the form of several gate concepts for the 1st stage gate report. The stage gate concepts resulting from the review meeting will inevitably be a mixture of the chosen alpha-, beta-, gamma- and delta-ideas.

\section{Case project details}

In total, the author attended over 15 brainstorms and review sessions. 10 projects were recorded comprising of approximately 40 hours of video and audio footage. However, only projects in Table 4 were chosen for extensive analysis as they were more comparable. The disregarded brainstorms had little effect on those comprehensively analysed, although they gave the researcher a deeper and more experienced insight into standard practice and routine. One of the rejected projects was used as a pilot study where stimuli were also provided during the individual idea generation stage. It was believed by the authors that the most vital variable to control between the each project studied was the stage of the design process that the brainstorm was conducted; this was constricted to the first stage ideas stage. Though the projects were raised from different business types within the case company, most briefs were open enough to allow solutions from all business types.

All of the brainstorms analysed comprised of attendees from within case company with varying job roles, though the majority were from the innovation department. The project managers also acted as brainstorm facilitators and were deemed very influential. It was observed that brainstorm sessions facilitated by novice or student designers were often different, as procedure was not always followed correctly. Therefore, it was decided that all projects facilitated by non-experienced designers were rejected for analysis, thus in all of the assessed projects, the project managers were experienced designers (Exp).

Table 4. Details of chosen case projects

\begin{tabular}{lllllll}
\hline $\begin{array}{l}\text { Project } \\
\text { number }\end{array}$ & $\begin{array}{l}\text { Stimuli } \\
\text { type }\end{array}$ & $\begin{array}{l}\text { Stage of Design } \\
\text { Process }\end{array}$ & $\begin{array}{l}\text { Business } \\
\text { type }\end{array}$ & $\begin{array}{l}\text { Project } \\
\text { type }\end{array}$ & $\begin{array}{l}\text { Project } \\
\text { manager }\end{array}$ & $\begin{array}{l}\text { Number of } \\
\text { participants }\end{array}$ \\
\hline 1 & A & Ideas & Food & Carrot & Exp. & 9 \\
2 & B & Ideas & Food & Customer & Exp. & 8 \\
3 & C & Ideas & Food & Customer & Exp. & 9 \\
4 & D & Ideas & Beverage & Carrot & Exp. & 9 \\
5 & None & Ideas & Special & Customer & Exp. & 6 \\
\hline
\end{tabular}




\section{Idea capture}

As part of the agreement with the case company the session was video and audio captured with synchronised capture of both PowerPoint slides and 'pen and ink' illustrations. The analysis software used to synchronise and code the data was Quindi@ (www.quindi.com) Meeting Companion which made the analysis and transcription more efficient (Figure 8). During each session the researcher participated as a designer, with no thought of evaluation of the session.

Participation enabled the researcher to gain better understanding of the process and made retrospective analysis of the session content easier.

When analysing the brainstorm sessions of each statement and in many instances the attached illustrations were tagged as one of the three stages of the creative process, either 'analysis', 'generation' or evaluation' derived from previous work (Howard et al. 2008b). It was later decided that the generation statements were to be the focus. Each idea was tagged to the audio and video footage of the meeting with the annotation and transcription of the idea stamped in the appropriate place along the meeting timeline (see figure 8). It must be noted that this approach does have its limitations, as an idea is time stamped at the point it is externalised to the group and not necessarily at the point of it conception.

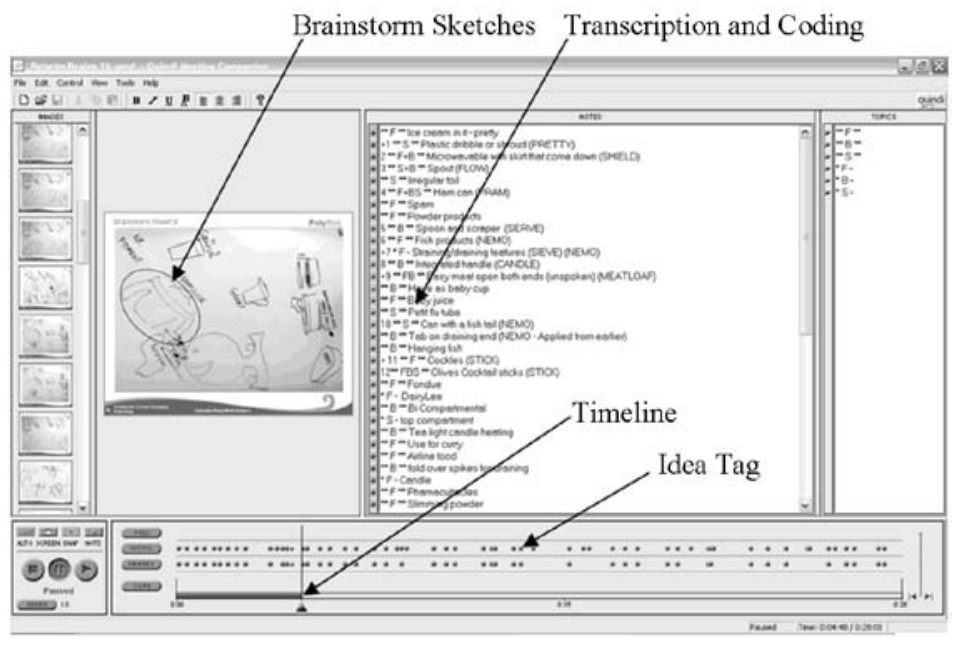

Figure 8. Screen shot of capture software

\section{Idea evaluation and selection}

In section 2.3 the theoretical performance criteria were conceived. However, it has been previously stated (Howard et al. 2008a), that in similar experiments regarding idea generation, the problems provided to the participants are artificial with no real issues and therefore the measures for each criterion are also often subjective and fuzzy. The method described in this paper attempts a pure objective evaluation of the performance criteria by linking the ideas generated to the evaluation and selection stages of the case company's innovation process.

The appropriateness of an idea depends on the group's collective evaluation of the idea during the review meeting (see figure 6). An appropriate idea is one which is selected, forming part of a design concepts proposed at the stage gate. The originality of the ideas can be assessed by they relate to the concepts put forward at the gate meeting. If an 
idea happened to be the first idea proposed relating to a particular concept, then it is considered original. If an idea follows from the original idea relating to the same concept, it is considered developmental. An idea is rated more unobvious the further away from the start of the brainstorm it is conceived. As all stimuli tools were introduced after 30 minutes of the brainstorm sessions, all ideas produced using them can be considered unobvious.

\section{Notations validation}

To validate this notation of ideas scheme, an inter-observer reliability check was conducted. Three independent researchers were asked to mark up 10 minutes of video and audio footage each, totalling at roughly 90 minutes real time. Each was given the classification scheme and asked to place a note where an idea had occurred along with a description of the idea. On comparison of the results the independent researchers missed only $14 \%$ of the ideas, identifying the rest correctly. It is likely that this $14 \%$ can be put down to audio quality and problems hearing each member of the group clearly in the recordings. It is also thought that the author was better placed to make judgment on each statement, due to having first hand experience of the brainstorm session and more practice using the markup scheme.

To validate the originality and appropriateness mark-up, an independent researcher was used for one of the case projects. The researcher was given the definitions of an idea and a concept and was asked to link the ideas to the concepts along with the sketches and video footage. The researcher was also given an example of this mark-up from another project to work with. After comparison it was found that $92 \%$ of the author's notation was correctly identified by the notation of the independent researcher.

\section{Results}

This section shows and discusses the results of the creative performance of the four different stimuli tools produced by the experiment. Each is analysed in terms of the rate of idea generation (section 5.1), the appropriateness (section 5.2), originality (section 5.3) and the unobviousness (section 5.4) of the ideas produced, along with the qualitative analysis throughout.

\section{Rate of idea generation}

Figure 9 shows the timelines of the 5 analysed brainstorm meetings. The first continuous line represents the free thinking brainstorming, above which each dot represents the occurrence of an alpha-idea. This is followed by the introduction of the various stimuli represented by the alternating dark and light grey lines above which each dot donates the occurrence of a beta-idea. The final shorter dark line represents the closing discussion. The bold numbers in the centre of each line total number of ideas during that section. The italic number above the dots represents the rate of idea generation (ideas/minute) up until that point. The italic figure underlined at the end of the stimuli section represents the rate of idea production of the beta-ideas only.

From Figure 9 along with the qualitative observations it is thought that the stimuli helped to maintain the rate of idea generation at this late stage of the brainstorm session. It is likely that this is due to the added interest and motivation experienced by the group from using the stimuli. However, there were more direct and apparent effects of the stimulus where elements of the stimuli actually inspired ideas; backed up by feedback from the participants "The 
segmentation one certainly sparked a few ideas". The use of stimuli in general also provided a starting point for participants' dialogue, sparking "secondary conversation that was quite productive actually".

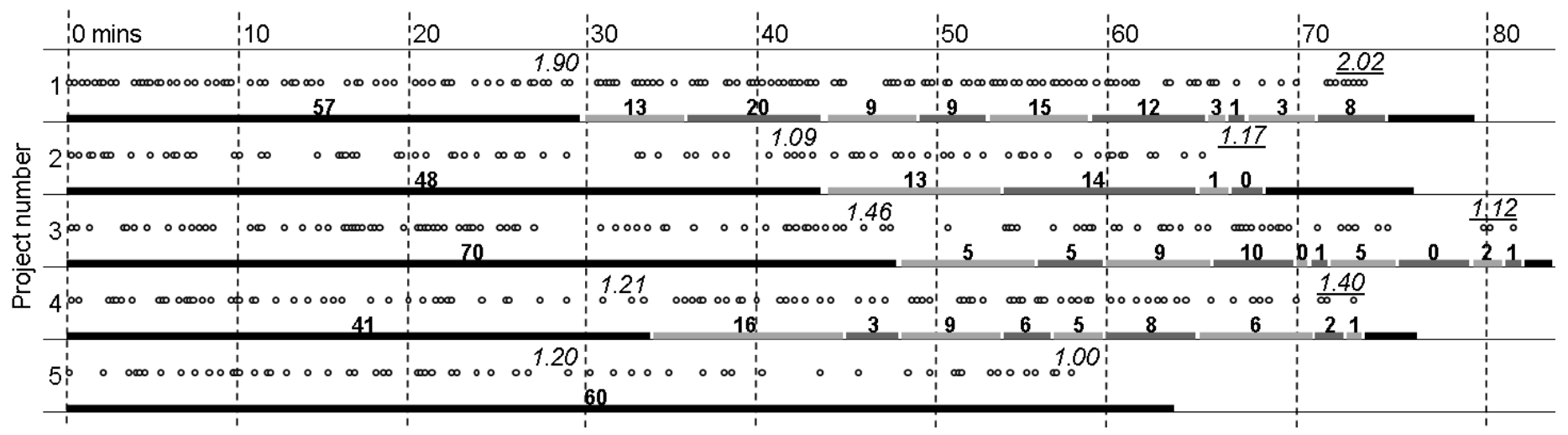

KEY: XX: Number of ideas in section $X . X X$ : Rate of ideas in section (ideas/min) $\underline{X . X X}$ : Rate of ideas under use (ideas/min) of stimuli

Figure 9. Rate of idea generation during brainstorm meetings.

Table 5 was constructed from the data in Figure 9. It showed that tool A produced the most ideas from a single stimulus, at 20 ideas. However, this figure may not be conclusive as the particular task and designers in project 1 were more conducive to idea generation, producing more ideas per unit time than in the other projects in the whole session, even prior to stimuli introduction. The random retrieval tools, A and C produced the best performing stimuli in terms of rate of idea generation at 2.5 ideas per second. However, as expected, this was contrasted by the higher number of stimuli which produced no ideas.

The most interesting and telling statistic details the rate of beta-idea generation to be higher than the rate of alphaidea production in project 1, 2 and 4 with only tool $C$ producing less ideas. The highest (relatively) performing was the Type D stimuli tool increasing the rate of idea production by $16 \%$. It also was observed that Type $C$ and $D$ tools produced a higher quantity of ideas, which were directly associated with the stimuli.

Table 5. Comparison of rates of idea generation of stimuli tools

\begin{tabular}{lllll}
\hline & $\begin{array}{l}\text { Tool A } \\
\text { Ext. Rand. } \\
\text { (project 1) }\end{array}$ & $\begin{array}{l}\text { Tool B } \\
\text { Ext. Guid. } \\
\text { (project 2) }\end{array}$ & $\begin{array}{l}\text { Tool C Int. } \\
\text { Rand. } \\
\text { (project 3) }\end{array}$ & $\begin{array}{l}\text { Tool D Int. } \\
\text { Guid. } \\
\text { (project 4) }\end{array}$ \\
\hline Most ideas from single stimulus & 20 & 14 & 10 & 16 \\
Highest idea rate of stimulus (Ideas/min) & 2.5 & 1.3 & 2.5 & 2.0 \\
Longest time of stimulus (min) & 8 & 11 & 8 & 11 \\
Total time using stimuli (min) & 46 & 24 & 34 & 40 \\
Number of stimuli producing $\leq 3$ ideas & 5 & 2 & 5 & 3 \\
Rate of beta-idea generation (Ideas/min) & 2.02 & 1.17 & 1.12 & 1.40 \\
Rate of generation of beta-ideas/alpha-ideas & 1.06 & 1.07 & 0.77 & $\underline{\mathbf{1 . 1 6}}$ \\
\hline
\end{tabular}




\section{Appropriateness of ideas}

Figure 10 shows where the appropriate ideas (that were included within the gate concepts) occurred and are denoted by circles stamped along the project timeline. It can be seen that the stimuli in general had a positive effect on the appropriateness of the ideas being generated. A higher proportion of gate ideas were produced under the influence of stimuli than could be expected at the particular late stage of the brainstorm session especially when compared against the control group, project 5 . There are also several examples in the data where the stimuli directly influenced the nature of the gate ideas, such as the 'segmentation' stimulus leading to a product idea containing "two flavours of pie".

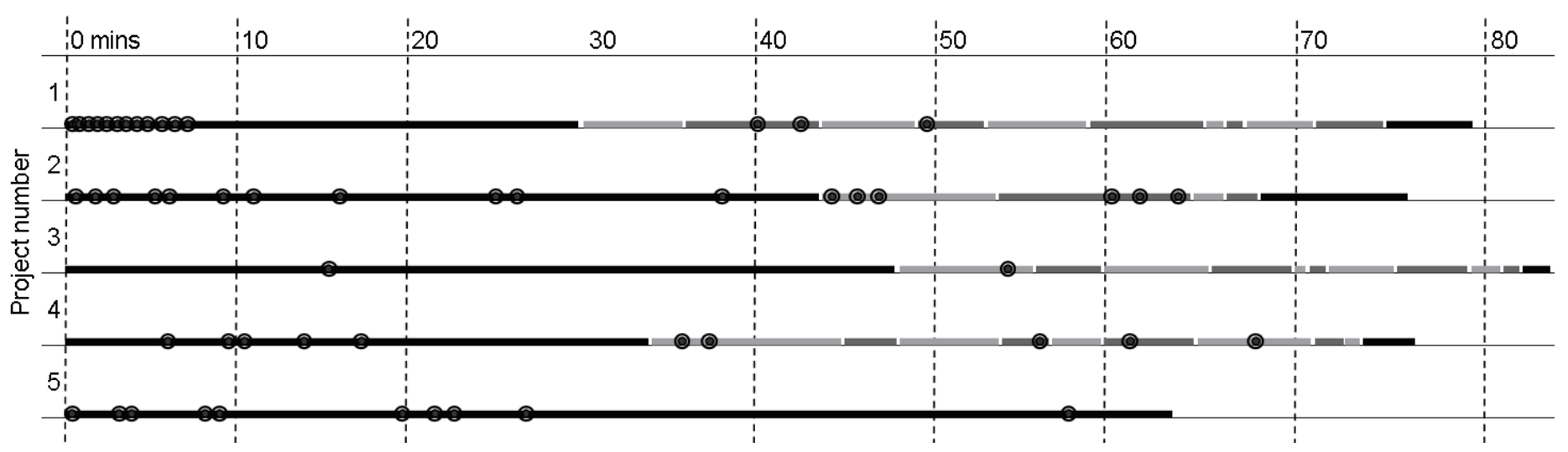

Figure 10. Appropriate ideas generated during brainstorm meetings.

From the comparison made in Table 6, it can be seen that the type B and D stimuli tool produced the most beta-gate ideas with 6 and 5 respectively. Both internal stimuli tools produced a higher quantity of beta-gate ideas relative to the total number of gate ideas at 0.5 each, providing compelling evidence for the potential behind internal generated stimuli. From the protocol analysis it was shown that the guided tools ( $B$ and $D$ ) produced more ideas both directly and abstractly inspired by the stimuli. Also, more of the stimuli proposed from the type $\mathrm{D}$ tool produced beta-gate ideas than any other stimuli tool.

Table 6. Comparison of Appropriate ideas produced of stimuli tools

\begin{tabular}{lllll}
\hline & $\begin{array}{l}\text { Tool A Ext. } \\
\text { Rand. } \\
\text { (project 1) }\end{array}$ & $\begin{array}{l}\text { Tool B Ext. } \\
\text { Guid. } \\
\text { (project 2) }\end{array}$ & $\begin{array}{l}\text { Tool C Int. } \\
\text { Rand. } \\
\text { (project 3) }\end{array}$ & $\begin{array}{l}\text { Tool D Int. } \\
\text { Guid. } \\
\text { (project 4) }\end{array}$ \\
\hline Number of beta-gate ideas & 3 & 6 & 1 & 5 \\
Number of directly inspired ideas & 1 & 3 & 0 & 1 \\
Number of abstractly inspired ideas & 0 & 3 & 1 & 3 \\
Number of beta-gate ideas/total gate ideas & 0.2 & 0.35 & 0.5 & 0.5 \\
Number of stimuli producing a gate idea & 2 & 2 & 1 & 4 \\
\hline
\end{tabular}




\section{Originality of ideas}

Figure 11. gives a breakdown of the beta-ideas produced during each project. From the graph it can be seen that on average only 1 original idea is produced as a result of a beta-idea (inspired by prescribed stimuli). This did not really support the initial belief that the diversity of the stimuli would lead to more original beta-gate ideas, instead suggesting that the stimuli aid in the development of concepts more 'how to' then 'what else'. Stimuli tool type D produced the most original ideas. Both directed tools produced a higher quantity of original ideas relative to the appropriate ideas. This was the opposite of what was expected. One reason for this may have been in the definition of originality being relative to a new concept rather than an original entity within the concept.

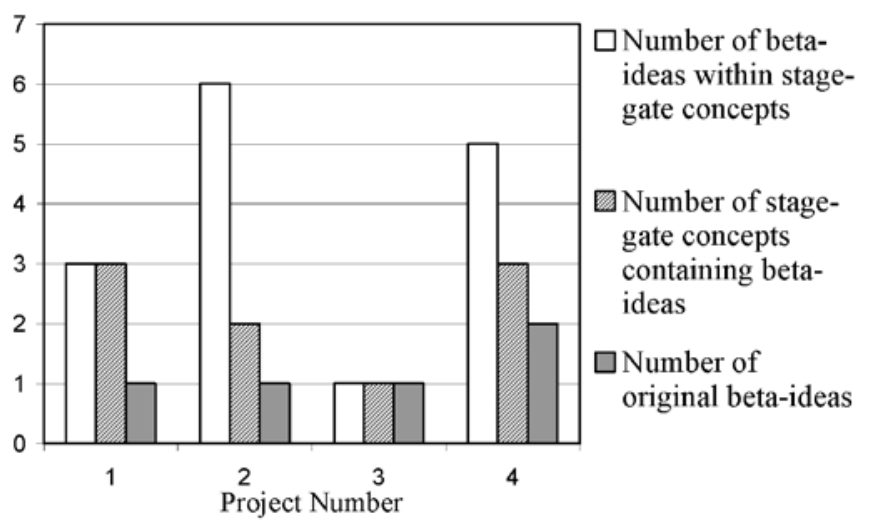

Figure 11. Breakdown of beta-ideas produced during each project

\section{Unobviousness of ideas}

As previously stated (section 2.3), unobviousness was difficult to determine over the course of this study and is more suited for the comparison of individual ideas. All beta-ideas produced are relatively unobvious due to the delay before the stimulus is prescribed. In terms of what is deemed a creative idea, final idea in project 5 (Figure 10) is the most unobvious as it is the latest idea that is both original and appropriate.

\section{Conclusions}

The performance of the different stimuli tools were considered in terms of the quantitative and qualitative observations throughout the various studies. However, as previously stated, the quantitative data must be analysed in light of the experimental limitations involved in the industry based study, using limited sample sizes and uncontrolled variables. One such uncontrolled variable that was highlighted by the results was the more unusual idea generation pattern of project group 1. On further investigation it was realised that this group differed from the others, as it was revealed that the task involved 'technology push' rather than 'market pull'. This is an interesting observation and warrants further investigation in future studies.

In many instances the stimuli did not work by directly inspiring new ideas, but by diverting designers onto a new train of thought, enabling fresh and new ideas. In terms of directly prompting ideas, the guided stimuli tools were more 
effective whereas the random external stimuli appeared particularly good at removing metal blocks. This could be because all participants could understand the stimuli; and knowing that they were retrieved randomly, the participants could take a relaxed attitude towards them.

It is believed that the type D stimuli tools out-performed the other tools in terms of the rate or frequency of ideas produced. This result is inline with expected outcome 1 (Section 2.4) which suggests the internally sourced stimuli should produce more ideas. This may have been because the stimuli retrieved by the internally sourced stimuli tools were generally more meaningful to the designers. When using the type B stimuli tool the meaning or understanding behind the stimulus was not always so easy to decipher. This is perhaps the most important criticism of the TRIZ inventive principles - without a thorough understanding of the principle, which may require a domain expert; the stimulus has reduced value. In this research it was seen that $50 \%$ of the stimuli proposed produce less than 3 ideas!

A higher proportion of beta appropriate ideas in relation to total number of appropriate ideas were produced when using internally sourced stimuli (outcome 2). It is believed that this was due to the higher relevance of the stimuli being retrieved. It was also shown that most ideas produced using the stimuli tools were developmental rather than original. However, the Sweeper (internal source - guided retrieval) stimuli tool produced the highest number of original ideas, interestingly outperforming the expectations of possible outcome 3 . The unobviousness of the ideas produced was hard to determine due to the research method. However, a higher frequency of ideas was produced at the late stages of the brainstorm sessions due to the use of all stimuli tools than could have been expected.

The guided stimuli tools, namely the TRIZ contradiction matrix and Sweeper, outperformed the randomly sourced stimuli tools in terms of all the creative performance criteria in line with expectation 4 . However, the actual performance of the tools is slightly different from the performance of the stimuli which they prescribe. In terms of usability, the random tools are extremely easy to implement and should be relatively quick to prepare and use.

Sweeper (the concept reuse tool) would take time to implement as a computer based tool but once installed could be used and assimilated very quickly. The TRIZ contradiction matrix tool requires setting up for each problem, although this process does provide other benefits to the understanding of the problem.

As a consequence of this research with the case company, several recommendations have now been actioned and implemented. The Sweeper tool, the pilot use of which has been described and analysed within this paper has now been programmed and implemented within the company. Further research with the collaborator has been agreed, attempting to widen the use of creativity tools to other areas of the case company, researching creativity for the embodiment and detailed design phases.

\section{Acknowledgments}

The work reported in this paper has been undertaken as part of the EPSRC Innovative Manufacturing Research Centre at The University of Bath (grant reference EP/E00184X/1) 


\section{References}

Altshuller, G.S., 1984. Creativity as an exact science : the theory of the solution of inventive problems Luxembourg: Gordon and Breach Science Publishers.

Altshuller, G.S., 1999. The innovation algorithm: TRIZ, systematic innovation and technical creativity Worcester, Mass.: Technical Innovation Center.

Amabile, T., 1982. Social psychology of creativity: A consensual assessment technique Journal of Personality and Social Psychology, 43 (5), 997-1013

Amabile, T., 1996. Creativity in context Boulder, Colorado: Westview press.

Avison, D., Lau, F., Myers, M. and Nielsen, P., 1999. Action research. Communications of the Acm, 42 (1), $94-97$

Benami, O. and Jin, Y., 2002. Creative stimulation in engineering design. DETC2002/DTM-34023, ASME 2002 Design Engineering Technical Conferences and Computer and Information in Engineering Conference, Montreal, Canada, 1-13.

Björk, E. and Ottosson, S., 2007. Aspects of consideration in product development research. Journal of Engineering Design, 18 (3), 195-207

Campos, A., Stokic, D. and Da Silva, R., 2004. Integrated Approach for Innovation and Problem Solving in Dynamic Virtual Enterprises. 2nd IEEE International conference on Industrial Informatics. Berlin, Germany.

Chakrabarti, A. and Tang, M.X., 1996. Generating conceptual solutions on FuncSION: evolution of a functional synthesiser. In: Sudweeks, F. \& Gero, J. 4th International Conference on Artificial Intelligence in Design (AID'96), Stanford University, USA: Kluwer Academic Publishers, The Netherlands, 603-622.

Cross, N., 2000. Engineering design methods strategies for product design Chichester: Wiley.

De Bono, E., 1985. Six thinking hats, 1st U.S. ed. Boston: Little, Brown.

Faure, C., 2004. Beyond Brainstorming: Effects of Different Group Procedures on Selection of Ideas and Satisfaction with the Process. The Journal of Creative Behavior, 38 (1), 13-34.

Frey, B., 1999. State support and creativity in the arts: some new considerations. Journal of Cultural Economics, 23 (12), 71-85.

Giess, M., Wild, P. and McMahon, C., 2008. The generation of faceted classification schemes for use in the organisation of engineering design documents. International Journal of Information Management, 28 (5), 379 390

Gordon, W., 1961. Synectics, the development of creative capacity New York: Harper.

Grossman, S. and Lloyd, P., 2006. Animal Crackers [online]. http://www.gocreate.com/animal/ [Accessed 2008].

Howard, T.J., 2008. Information Management for Creative Stimuli in Engineering Design. PhD. University of Bath. 
Howard, T.J., Culley, S.J. and Dekoninck, E.A., 2006. Information as an input into the creative process. In: Marjanovic, D. 9th International Design Conference DESIGN 06, Dubrovnik, 549-556.

Howard, T.J., Culley, S.J. and Dekoninck, E.A., 2007. Creativity in the Engineering Design Process. 16th International Conference on Engineering Design, ICED 07, Paris.

Howard, T.J., Culley, S.J. and Dekoninck, E.A., 2008a. Creative stimulation in conceptual design: An analysis of industrial case studies. ASME 2008 International Design Engineering Technical Conferences \& Computers and Information in Engineering Conference IDETC/CIE 2008, Brooklyn, New York, USA

Howard, T.J., Culley, S.J. and Dekoninck, E.A., 2008b. Describing the creative design process by the integration of engineering design and cognitive psychology literature. Design Studies, 29 (2), 160-180.

Howard, T.J., Culley, S.J. and Dekoninck, E.A., 2009. Stimulating Creativity: A more practical alternative to TRIZ. 17th International Conference on Engineering Design, ICED'09, Stanford, California.

Isaksen, S.G. and Gaulin, J.P., 2005. A Reexamination of Brainstorming Research: Implications for Research and Practice. Gifted Child Quarterly, 49 (4), 315-329.

Kim, Y., Jin, S. and Lee, H., 2005. Dual protocol analysis based on design information and design process: a case study. In: Gero, J. \& Bonnardel, N. Studying designers '05, Key centre of design computing and cognition, University of Sydney, 71-85.

Kristensson, P., Magnusson, P. and Matthing, J., 2002. Users as a Hidden Resource for Creativity: Findings from an Experimental Study on User Involvement. Creativity and Innovation Management, 11 (1), 55-62.

Lubart, T., 2005. How can computers be partners in the creative process: Classification and commentary on the Special Issue. International Journal of Human-Computer Studies, 63 (4-5), 365-369.

Mann, D., 2002. Hands on systematic innovation Belgium: Creax.

Massetti, B., 1996. An Empirical Examination of the Value of Creativity Support Systems on Idea Generation. MIS quarterly, 20 (1), 83-97.

Mauzy, J. and Harriman, R., 2003. Three climates of creativity. Research -Technology Management, 46 (3), 27-30.

Mumford, M., 2000. Managing Creative People: Strategies and Tactics for Innovation. Human Resource Management Review, 10 (3), 313-351

Nijstad, B.A., Stroebe, W. and Lodewijkx, H.F.M., 2002. Cognitive stimulation and interference in groups: Exposure effects in an idea generation task. Journal of Experimental Social Psychology, 38 (16), 535-544.

Osborn, A.F., 1953. Applied imagination; principles and procedures of creative thinking New York: Scribner.

Pahl, A., Newnes, L. and McMahon, C., 2007. A generic model for creativity and innovation: overview for early phases of engineering design. Journal of Design Research 6(1-2), 5-44. 
Pahl, G. and Beitz, W., 1984. Engineering Design: A systematic approach London: The Design Council.

Perttula, M. and Sipila, P., 2007. The idea exposure paradigm in design idea generation. Journal of Engineering Design, 18 (1), 93-102.

Prahalad, C. and Ramaswamy, V., 2003. The New Frontier of Experience Innovation. MIT Sloan Management Review, 44 (4), 12-18.

Santanen, E., Briggs, R. and De Vreede, G., 2004. Causal Relationships in Creative Problem Solving: Comparing Facilitation Interventions for Ideation. Journal of Management Information Systems, 20 (4), 167-197.

Santanen, E. and De Vreede, G., 2004. Creative approaches to measuring creativity: comparing the effectiveness of four divergence thinkLets. 37th Hawaii International Conference on System Sciences. Hawaii, USA.

Soosay, C. and Hyland, P., 2004. Driving Innovation in Logistics: Case Studies in Distribution Centres. Creativity and Innovation Management, 13 (1), 41-51.

Sternberg, R. and Lubart, T., 1993. Investing in creativity. Psychological inquiry, 4 (3), 229-233

Taghavi, T., Ghiasi, G., Ranjan, A., Raje, S. and Sarrafzadeh, M., 2004. Innovate or Perish: FPGA Physical Design. ISPD'04. Phoenix, Arizona, USA.

Wierenga, B., 1998. The Dependent Variable in Research into the Effects of Creativity Support Systems: Quality and Quantity of Ideas. MIS quarterly, 22 (1), 89-93.

Zusman, A. and Zlotin, B., 1999. Overview of Creative Methods. The TRIZ Journal. (online only - http://www.trizjournal.com/L, 